\title{
AN INVESTIGATION OF EFFECT OF LANGUAGE BARRIER ON EFFECTIVE COMMUNICATION FOR THE PROVISION OF QUALITY HEALTHCARE: A CASE OF KERICHO COUNTY HEALTH FACILITIES, KENYA
}

\author{
G. A Obel \\ Lecturer, Kenya Highlands University \\ Email: achienggladys68@gmail.com
}

Dr. Peter Muhoro Mwangi

Department of Languages and Humanities Mount Kenya University.

\author{
Dr. Kimetto Richard \\ Lecturer of Business Administration, Great Lakes University of Kisumu \\ Associate Lecturer, Kenya Highlands University \\ Email: richkimetto2030@gmail.com
}

DOI: $10.31364 / S C I R J / v 8 . i 2.2020 . P 0220743$

http://dx.doi.org/10.31364/SCIRJ/v8.i2.2020.P0220743

\begin{abstract}
The community within the County is heterogeneous and multilingual, as a result, a number of challenges arise in communication during clinical sessions with expatriate, foreign and local medical staff. Little efforts have been made to bridge the gap brought about by language barrier so, patient physician interaction is compromised and quality care threatened. This study therefore was an investigation of the effect of language barrier on effective communication for the provision of quality healthcare: in Kericho County health facilities, Kenya. The specific objectives of the study were to: examine the effect of phonology on effective communication; find out the effect of mother-tongue interference on effective communication; determine the effect of grammatical distortion on effective communication; and investigate the effect of lexical deviation on effective communication for the provision of quality healthcare in Kericho County health facilities, Kenya. The study was based The Behaviorist and The Contrastive Analysis Theories. The dependent variable was effective communication during the provision of quality healthcare while the independent variables were language barriers (phonologies, mother tongue interference, grammatical distortion, and lexical deviation). The study employed a mixed research approach. The study targeted the 136 health facilities and 2406 healthcare workers in the County. The sample sizes were 100 health facilities and 342 healthcare workers and were calculated from Yamane model. A multi staged sampling technique was used. A structured questionnaire and interview schedule were used in data collection. Research tools were pre-tested for reliability using Cronbach's alpha $(\alpha)$ during piloting, and triangulation was used in ascertaining the validity of the instruments. Data was analyzed through correlation and regression models and results presented in tables and figures. Phonology had a statistically significant positive correlation $(\mathrm{R}=.627 ; \mathrm{P}<.05)$ with effective communication during the provision of quality health care. It had a statistically significant effect of $\left(F_{(1,295)}=123.221 ; \mathrm{P}<.05\right)$ accounting for approximately $39.3 \%$ variations in effective communication during the provision of quality health care. Mother tongue interference had a statistically significant moderate negative correlation $(\mathrm{R}=.524 ; \mathrm{P}<.05)$ with effective communication during the provision of quality health care. It had a statistically significant effect on effective communication $\left(F_{(1,295)}=101.360\right.$; $\mathrm{P}<.05)$ accounting for approximately $27.5 \%$ variations on effective communication during the provision of quality health care. Grammatical distortion had a statistically significant weak negative correlation $(\mathrm{R}=.215 ; \mathrm{P}<.05)$ with effective communication during the provision of quality health care. It had a statistically significant effect on effective communication $\left(F_{(1,295)}=23.111\right.$; $\mathrm{P}<.05)$ accounting for approximately $4.6 \%$ variations on effective communication during the provision of quality health care. In conclusion, language barriers had significant effect on effective communication during the provision of quality health care in Kericho County hospitals.
\end{abstract}




\section{INTRODUCTION}

There are many challenges facing healthcare in the world today, one of which is the role language plays in health communication. Language is a system of human communication, spoken or written comprising used words and enabling people to express their feelings and thoughts. When two or more people face difficulties during communication or experience a complete lack of it, it is referred to as language barrier. Language barrier may have considerable impact on verbal communication and as a result can affect access to quality care.

According to (Russell, 2009), many linguistically and culturally diverse patients, as a result of their inability to communicate with their healthcare providers, experience inadequate access to healthcare and poorer health status. Notable is the fact that, in the absence of effective communication, health providers experience many challenges which include simple care activities such as assessment, diagnosis and treatment, (Flores, 2005). These point to the fact that language barrier can have severe effects in the medical context.

Globally, the world has presented a situation of travelling abroad for medical care. In most cases, the patients and the healthcare personnel do not share a common language. Jansson, (2014) aptly points out that the main body of research has focused on investigating language issues in healthcare in the context of the immigrant in the United States of America, Europe, Australia and India as well as other countries with the aim of providing equitable and quality healthcare.

Holmquist(2011) notes that if a customer and a health provider fail to communicate effectively, this would have adverse impact on the whole service. Holmquist (2012) in the same context, emphasizes that language barrier has been demonstrated empirically to have various negative consequences in patients. In addition, (Jacobs et al., 2006), also underscore the fact that an efficient dialogue between a doctor and a patient is "of diagnostic import and therapeutic benefit".

In a study in the United States of America covering eleven ambulatory clinics in Boston, in the year 2000, language barrier was shown to play a major role in outpatient drug complications. A multiple regression analysis of the same study revealed that having a primary language other than English or Spanish was an independent predictor of patient reported drug complications. (Middle East Journal of Nursing, Vol. 7, Issue 4, August 2013). This journal highlighted the fact that the level of overall satisfaction was found to be significantly lower among patients who reported problems related to medication use compared to those who did not. The Western European countries including those of Northern Europe (Scandinavia) have become increasingly multicultural. In Norway for instance, immigrants account for about $12.2 \%$ of the total population while in Oslo, which is the nation's capital it stands at 28\% (This is according to Statistics, Norway 2012). Integrating the non-western immigrant groups into existing healthcare services has had severe consequences, in addition the health of the immigrants and that of the Norwegians differs greatly (Kumar, 2008). However, he notes that in all ethnic groups those with the highest education reported good health more frequently than others.

Saudi Arabia has a shortage of nursing staff and relies on expatriates from the Philippines, India, Malaysia and South Africa. The expatriates are non-Arabic speaking (Middle East Journal of Nursing Vol. 7 Issue 4, August 2013). The journal further highlights 
communication problems which have affected patient satisfaction and led to serious medical errors. In the light of what has been stated, language discordance can be detrimental to health care and so proper measures ought to be put in place to cushion patients all over the world from the dangers of language barrier, not only between physicians and their patients, but also between physicians themselves.

In South Africa, the health sector has been characterized by disorganized interpersonal relationships regarding interpreting practices. Attempts have been made to use interpreting services rendered by both professionally trained as well as ad-hoc interpreters to solve the communication problem between patients and medical practitioners. It is important to note that when these two types of interpreters are used in consultation with a medical practitioner, the main aim being to get the correct and relevant message across to both patient and the medical practitioner, this impacts positively on language communication. Whether that message gets across as intended or not indicates the quality of the interpreted product.

According to reports by Kenya National Bureau of Statistics, (KNBS) Kenya's population is currently estimated at 48 million. Being a country with diverse culture, ethnic groups and languages, about half of this population has Limited English Proficiency (LEP). This study focused on (LEP) and the total lack of the language group in hospitals in Kericho County, Kenya. The hospitals also face a shortage of medical staff in certain areas of specialization and have to depend on expatriates. Consequently, there arises difficulties in communication and these hinder patients from accessing quality healthcare at the hospital. The objective of this study was to investigate the effect of language barrier in effective communication for the provision of quality healthcare, and to suggest possible interventions to mitigate the effects of language barriers on the same.

\section{ABRREVIATION AND ACRONYMNS}

\section{LEP Low English Proficiency}

ES English Speaking

TL Target Language

SL Source Language

$\mathbf{L}_{1} \quad$ First Language

$\mathbf{L}_{2} \quad$ Second Language

CA Contrastive Analysis

SLA Second Language Acquisition

UK University of Kentucky

WHO World Health Organization

USA United States of America

HIV Human Immuno - Deficiency Virus

STIs Sexually Transmitted Infections

\section{OPERATIONAL DEFINITION OF TERMS}

\section{Language}

Is the system of human communications, either spoken or written consisting of used words and enabling people to express their feelings and thoughts. 


\section{Language barrier}

Difficulties that two or more people who do not share a common language face during communication. Also refer to a complete lack of communication.

\section{Limited English Proficiency (LEP)}

People whose natural language is not English and whose skills in English are limited.

\section{Healthcare Services}

Services which include dealing with diagnosis treatment of disease or the promotion, maintenance and restoration of health.

\section{Ad-hoc interpreter}

Is any person who is not trained in interpreting but called upon to interpret e.g. a family member or a bilingual staff?

\section{Access to Care}

The ability to obtain, or use services relative to the actual need for care.

\section{Source Language}

Language of the speaker being interpreted from.

\section{Target Language}

The language one is interpreting into. In this context it is performed for patients with Limited English Proficiency, (LEP).

\section{Health}

\section{Chapter ONE}

\section{INTRODUCTION}

\section{A. 1.1 Overview}

This chapter presents the introductory part of the study. It basically covers the background of the study, the statement of the problem, the purpose of the study, objectives of the study, hypotheses, significance, scope, as well as limitations and delimitations.

\section{B. 1.2 Background of the Study}

There are many challenges facing healthcare in the world today, one of which is the role language plays in health communication. Language is a system of human communication, spoken or written comprising used words and enabling people to express their feelings and thoughts. When two or more people face difficulties during communication or experience a complete lack of it, it is referred to as language barrier. Language barrier may have considerable impact on verbal communication and as a result can affect access to quality care.

According to (Russell, 2009), many linguistically and culturally diverse patients, as a result of their inability to communic ate with their healthcare providers, experience inadequate access to healthcare and poorer health status. Notable is the fact that, in the absence of effective communication, health providers experience many challenges which include simple care activities such as 
assessment, diagnosis and treatment, (Flores, 2005). These point to the fact that language barrier can have severe effects in the medical context.

Globally, the world has presented a situation of travelling abroad for medical care. In most cases, the patients and the healthcare personnel do not share a common language. Jansson, (2014) aptly points out that the main body of research has focused on investigating language issues in healthcare in the context of the immigrant in the United States of America, Europe, Australia and India as well as other countries with the aim of providing equitable and quality healthcare.

Holmquist(2011) notes that if a customer and a health provider fail to communicate effectively, this would have adverse impact on the whole service. Holmquist (2012) in the same context, emphasizes that language barrier has been demonstrated empirically to have various negative consequences in patients. In addition, (Jacobs et al., 2006), also underscore the fact that an efficient dialogue between a doctor and a patient is "of diagnostic import and therapeutic benefit".

In a study in the United States of America covering eleven ambulatory clinics in Boston, in the year 2000, language barrier was shown to play a major role in outpatient drug complications. A multiple regression analysis of the same study revealed that having a primary language other than English or Spanish was an independent predictor of patient reported drug complications. (Middle East Journal of Nursing, Vol. 7, Issue 4, August 2013). This journal highlighted the fact that the level of overall satisfaction was found to be significantly lower among patients who reported problems related to medication use compared to those who did not.

The Western European countries including those of Northern Europe (Scandinavia) have become increasingly multicultural. In Norway for instance, immigrants account for about $12.2 \%$ of the total population while in Oslo, which is the nation's capital it stands at 28\% (This is according to Statistics, Norway 2012). Integrating the non-western immigrant groups into existing healthcare services has had severe consequences, in addition the health of the immigrants and that of the Norwegians differs greatly (Kumar, 2008). However, he notes that in all ethnic groups those with the highest education reported good health more frequently than others.

Saudi Arabia has a shortage of nursing staff and relies on expatriates from the Philippines, India, Malaysia and South Africa. The expatriates are non-Arabic speaking (Middle East Journal of Nursing Vol. 7 Issue 4, August 2013). The journal further highlights communication problems which have affected patient satisfaction and led to serious medical errors. In the light of what has been stated, language discordance can be detrimental to health care and so proper measures ought to be put in place to cushion patients all over the world from the dangers of language barrier, not only between physicians and their patients, but also between physicians themselves.

In South Africa, the health sector has been characterized by disorganized interpersonal relationships regarding interpreting practices. Attempts have been made to use interpreting services rendered by both professionally trained as well as ad-hoc interpreters to solve the communication problem between patients and medical practitioners. It is important to note that when these two types of interpreters are used in consultation with a medical practitioner, the main aim being to get the correct and 
relevant message across to both patient and the medical practitioner, this impacts positively on language communication. Whether that message gets across as intended or not indicates the quality of the interpreted product.

According to reports by Kenya National Bureau of Statistics, (KNBS) Kenya's population is currently estimated at 48 million. Being a country with diverse culture, ethnic groups and languages, about half of this population has Limited English Proficiency (LEP). This study focused on (LEP) and the total lack of the language group in hospitals in Kericho County, Kenya. The hospitals also face a shortage of medical staff in certain areas of specialization and have to depend on expatriates. Consequently, there arises difficulties in communication and these hinder patients from accessing quality healthcare at the hospital. The objective of this study was to investigate the effect of language barrier in effective communication for the provision of quality healthcare, and to suggest possible interventions to mitigate the effects of language barriers on the same.

\section{1.3 Statement of the Problem}

Kericho County is cosmopolitan and hosts linguistically heterogeneous population. It provides appropriate conditions for studying communication problems brought about by the existence of multilingual community. Local languages remain the principal medium through which service provider - client communication takes place.The staff also comes from a diversity of linguistic backgrounds both Kenyan and non - Kenyan. There are expatriates from the Republic of China, India, Cuba, the United States of America and the United Kingdom. In some cases, English is not the main language for doctor - patient interaction. The extent to which a doctor from non-English speaking countries is able to communicate effectively with their patient is the main agenda of this research. It therefore follows that there is a gap in most of health institutions in the county because the physician and the patient cannot communicate effectively. This study aimed at investigating the effect of language barrier on quality healthcare in these health facilities and suggesting possible solutions to the problems of language barrier.

\section{1.4 Purpose of the Study}

The study investigated the Effect of Language barrier on effective communication for the provision of quality healthcare in Kericho County health facilities, Kenya.

\section{E. 1.5 Specific Objectives}

i) To examine the effect of phonology on effective communication for the provision of quality healthcare in Kericho County health facilities, Kenya.

ii) To find out the effect of mother-tongue interference on effective communication for the provision of quality healthcare in Kericho County health facilities, Kenya.

iii) To determine the effect of grammatical distortion on effective communication for the provision of quality healthcare in Kericho County health facilities, Kenya.

iv) To investigate the effect of lexical deviation on effective communication for the provision of quality healthcare in Kericho County health facilities, Kenya. 


\section{F. 1.6 Hypotheses of the study}

The study was based on the following research hypotheses:

i. $\mathrm{H}_{0}$ : There is no statistically significant effect of phonology on effective communication for the provision of quality healthcare in Kericho County health facilities, Kenya.

ii. $\mathrm{H}_{0}$ : There is no statistically significant effect of mother-tongue interference on effective communication for the provision of quality healthcare in Kericho County health facilities, Kenya.

iii. $\mathrm{H}_{0}$ : There is no statistically significant effect of grammatical distortion on effective communication for the provision of quality healthcare in Kericho County health facilities, Kenya.

iv. $\mathrm{H}_{0}$ : There is no statistically significant effect of lexical deviation on effective communication for the provision of quality healthcare in Kericho County health facilities, Kenya.

\section{G. 1.7 Significance of the Study}

It would gauge the gravity with which language and or communication impacts on (LEP) patients who visit hospitals in Kericho County health facilities, Kenya. It would enhance accuracy in assessment,diagnosis, prescription and dispensation thus improving healthcare to the vulnerable. It would also establish, show and reduce client's treatment risks, health provider's risk of malpractice and encourage more use of health promotions by patients and providers. It would further encourage the use of health education resources and higher participation in preventive care. Language barrier has been the best documented source of disparities in healthcare and since this study addresses it, it would finally provide priorities to the (LEP) group and open doors for other researchers to provide more knowledge in this area. Academicians in health institutions of learning, health facilities, health organizations, health ministries and departments and the country would thus benefit from this study. The knowledge obtained in this research would enable the health care providers to take a more proactive rather than a reactive approach to health care services thus quality health care will be provided.

\section{H. 1.8 Scope and Limitations}

The researcher faced difficulties in administering the questionnaires especially in an environment where some of the respondents were uncooperative. This was so since in some instances, what was being investigated involved experiences in their day to day setting. In some cases, the researcher was forced to seek the assistance of the health officer in charge, especially where the respondents delayed in completing the questionnaires. The researcher also had to persuade and constantly follow up the respondents to get feedbacks in good time. The study was limited to effect of language barrier on effective communication for the provision of quality healthcare in Kericho County health facilities, Kenya.

\section{1.9 Delimitation}

The study was confined to the Kericho County, health facilities. A sample population was studied and was representative of the targeted population in the study area. 


\section{Chapter Two}

\section{LITERATURE REVIEW}

\section{J. 2.0Introduction}

It examines issues relating to the topic in the subsequent sub-topics as follows: Empirical Literature, Prescribed Treatment, Medication Errors, Social Distance, Chronic Disease Management and Satisfaction with Care Experience. Other areas in this review also include: Effects of Phonological barrier, Effects of Mother-tongue Interference, Effects of Grammatical Distortion, Effects of Lexical barrier, Verbal Communication as in Medical jargon, Access to Health care information, Language Concordance and Analytical Literature Review. Also included are: The Conceptual Framework and Theoretical Literature Review.

\section{K. 2.1Empirical Literature}

Language puts the patient at a different communication level and the quality of their communication with their physicians determines their health outcomes. It can be described as the most essential technology for medicine (Jackson, 1998) and according to him it is the principle instrument of conducting its work. This section focuses on empirical literature that is related to the topic of study. The researcher attempts to examine and bring out the gap brought about by language discordance during clinical encounters between physicians and patients who speak different languages as follows;-

\section{1) 2.1.1 Effects of Phonological Barrier}

Phonetics is the process of describing sounds the way they are used in speech, and phonology is the study of the non-concrete illustration of sounds in a particular language. A phoneme is which is defined as the smallest unit of speech sounding a language; differentiates one word from the other (Roach, 2009).

Patients who visit hospitals communicate with their physicians in dialects, accents, cadences and slang. The physicians from other parts of the world or regions often find it hard to comprehend them. Also, they describe their experiences uniquely. Pronunciation problems are prevalent amongst most Kenyan ethnic communities.

In 2002, Torgesena and Mathes carried out a study on phonological deficiency in diagnosis of reading disability. In their study which was carried out among children indicated that phonemic ability is very important in effective communication. According to Gillon (2004) it is important for one to understand the relationship between the word structure and the sound it produces. Phonology of language is thus important in effective communication. The current study will specifically look at the effect of phonology in effecting communication between patients and medical officers during the provision of healthcare.

Torgesen (1999) asserted that phonology is very crucial in instilling structures and combinations which influences the formation of the spoken language. Unlike in reading which require the pronunciation of distinct phonemes, oral language communication requires the combination of individual sounds to form a larger sound units(Gillon, 2004). 
Dodd et al., (2008) conducted a study which investigated the 'impact of selecting different contrasts in phonological therapy'.

They reported that in cases of phonetic barriers in communication, repetitions of words produced positive results though much time was spent in repeating words. The study further indicated a statistically significant positive effect of phonology competency on effective communication.

\section{2) 2.1.2Effects of Mother Tongue Interference}

Mother-tongue is the first language learned at home during childhood and can be tillunderstood by the individual in question (Kenya Bureau of Statistics, 2010). Mother is used as an effective language in expression emotions, and becomes the most common language in healthcare among patience as it requires no interpretation which may result in erroneous understanding (Bowen, 2001).

Most (LEP) patients including most foreign language learners often make mistakes when communicating using English collocations because they don't know their meanings. The native language interference can easily be noticed and the replacements are inappropriate, the result is inhibition of communication. According to (Collins et al., 2002) language barrier can reduce the ability of the patient to follow the instructions of the physician; it may also lead to overtreatment of patients, and procedures that carry additional risks and cost to the patient.

In 2018, Ali and Watson carried out a study. The study which was conducted in hospitals in England indicated that effective communication was a very important component in the provision of quality healthcare regardless of the medical officer's specialty area. Language barrier was found to be common in hospitals which were frequented by immigrants whose languages were different from those spoken by the medical officers. In most of the cases, the use of language interpreters was sought but this slowed the effective and timely care to such patients. The current study will however look at the effect of mother-tongue interference in effecting communication between patients and medical officers during the provision of healthcare in Kericho County health facilities, Kenya.

Ali and Watson (2018) findings echoed earlier researchers' findings that asserted that effective communication is mandatory for the provision of the necessary healthcare (Collineet al., 2002). This makes the language of communication important for the needed communication to occur. Hornberger et al. (1996)also reiterated the same concern in the quote below:

"The clinician must communicate with the patient or a proxy (e.g., a family member) to learn about the patient's problems, needs, and concerns and to convey information and offer recommendations about care"

All parties in the communication system must at least understand the content of communication in any effective communication. Earlier studies reported that language barriers including mother-tongue interference generally result in poor access of health care services especially among the low income individuals (Torres 1998; Woloshinet al. 1995).

\section{3) 2.1.3Effects of Grammatical Distortion}


The key function of the human language is to convey information. Language is a system that combines parts into infinitely many ways. This can be observed in word order restrictions as in the following:
a) The man killed the elephant
b) A man killed the elephant.
c) The elephant a man killed.
d) A man the elephant killed.

Sentences (c) and (d) are distorted and therefore unacceptable to native speakers of English. This means that there are syntactical rules that constrain which words can be combined, ordered, sometimes in groups, or with respect to each other. Such rules play important roles in the understanding of syntax.

A survey carried out in the USA Local Health Department in 1993 indicated that language barriers affected patients' ability to get health care services. Grammatical distortion resulted in distortion of the intended meaning of the spoken word. This lead to giving wrong medication to the patient in some cases (U.S. Conference of Local Health Officers 1993).

A study done by in Latin America revealed that people with low English proficiency made $20 \%$ less hospital visits compared to those who had higher English proficiency. David and Rhee (1998) in a similar study, indicated that language barrier was associated with patients' dissatisfactions.

\section{4) 2.1.4Effects of Lexical Barrier}

Words or phrases can be coined. This is found in the invention of new words. Lexical deviation occurs when replacing words from one language to another. This is demonstrated when adolescents and adults make mistakes while changing languages over words, phrases and sentences because they lack the linguistic competence necessary for fluent code switching (Paradiset al., 2011). The constant replacements of items during communication some of which may not be appropriate or relevant, contribute to lexical barrier in communication. (Sobralske, 2011) aptly points out that this can have adverse effect. Thus, according to him lexical deviation widens the health literacy gap and increases health disparities.

A survey by Trempe and Lussier (2011) found that larger proportion of health service workers commonly used English language in the workplace which was opposed to patients who preferred the use of their mother tongues when they visited health facilities. A study by Anne-Marie et al. (2013) indicated that physicians use a second language in their working places. In some cases, the use of translated documents and interpreters allow for communication but the understanding between the parties involved is not guaranteed. The use of translated documents may work but only when the translator first explains the items to the patients in his/her language. She further noted that written documents bring into play the question of literacy of the patients since they must be able to read and comprehend the content of the written documents. 


\section{2.2Theoretical Literature Review}

\section{1) 2.2.1 Second Language Acquisition Theories}

This study was guided by The Second Language Acquisition (SLA) theories, one of which is the Behaviorist theory. This theory influenced language learning. It is associated with the great psychologists, B.F. Skinner and J.B. Waston. The central claim of this theory is that the properties of $\mathrm{L}_{1}$ influence the course and or route of learning of $\mathrm{L}_{2}$. This is because the learner transfers sounds, structures and meanings. This transfer is argued to be helpful if it is positive and if it enhances the learning of the target language. If it inhibits the learning of $\mathrm{L}_{2}$ it is referred to as interference. It was also considered inhibitive if what is suppressed or repeated by the learner are errors.

Another theory the researcher considered appropriate for this study was the Contrastive Analysis theory. According to this theory, the prime cause of errors in $\mathrm{L}_{2}$ is interference from the learners' $\mathrm{L}_{1}$. This hypothesis is based on the Transfer theory which postulates that prior learning affects subsequent learning. The $\mathrm{L}_{2}$ plays an important role and is granted prominence widely in settings like education, judicial language, health institutions, commerce, and in most States it acquires the status of official language, as is the case of English in Kenya. It is used by immigrants. It is the official language in Kenya, Uganda, Nigeria and Zimbabwe. It is clear therefore that it is the language of communication in our health institutions. So, on examining language barrier and how it affects quality healthcare, these theories enabled the researcher to justify that the learner's pronunciation, accent, mother-tongue interference, grammatical distortion and lexical deviation affect their $\mathrm{L}_{2}$, consequently inhibiting communication between the health providers and their patients.

\section{2.3 Conceptual Framework}

Language barrier was the independent variable, while effective communication during the provision of was the dependent variable. In relation to the literature, there are great risks in the provision of quality healthcare faced by both the (LEP) patients and the healthcare providers. In communication, phonological problems, mother tongue interference, the use of medical jargon and language discordance can lead to malpractice, and misdiagnoses. Language barrier could also affect assessment, diagnosis, prescription and dispensation. (Sertelet al, 2013) also observed that language barrier may result in reduced health literacy.

The intervening variables in this study were leadership and management commitment. Effective leadership and management commitment enhances effective interpretation processes, and as a result there was likely to be proper diagnosis, prescription and dispensation. It is this that would lead to effective communication during the provision of quality healthcare in healthcare institutions. In terms of government policies, positive contribution in financing and the provision of adequate and professional human resource and necessary health facilities would assist LEP patients to access quality healthcare.

However, failure by the government to provide the above could hinder the process of providing quality healthcare services to its citizens.

The conceptual framework shows the relationship between language barrier, intervening variables and clinical service provision. 


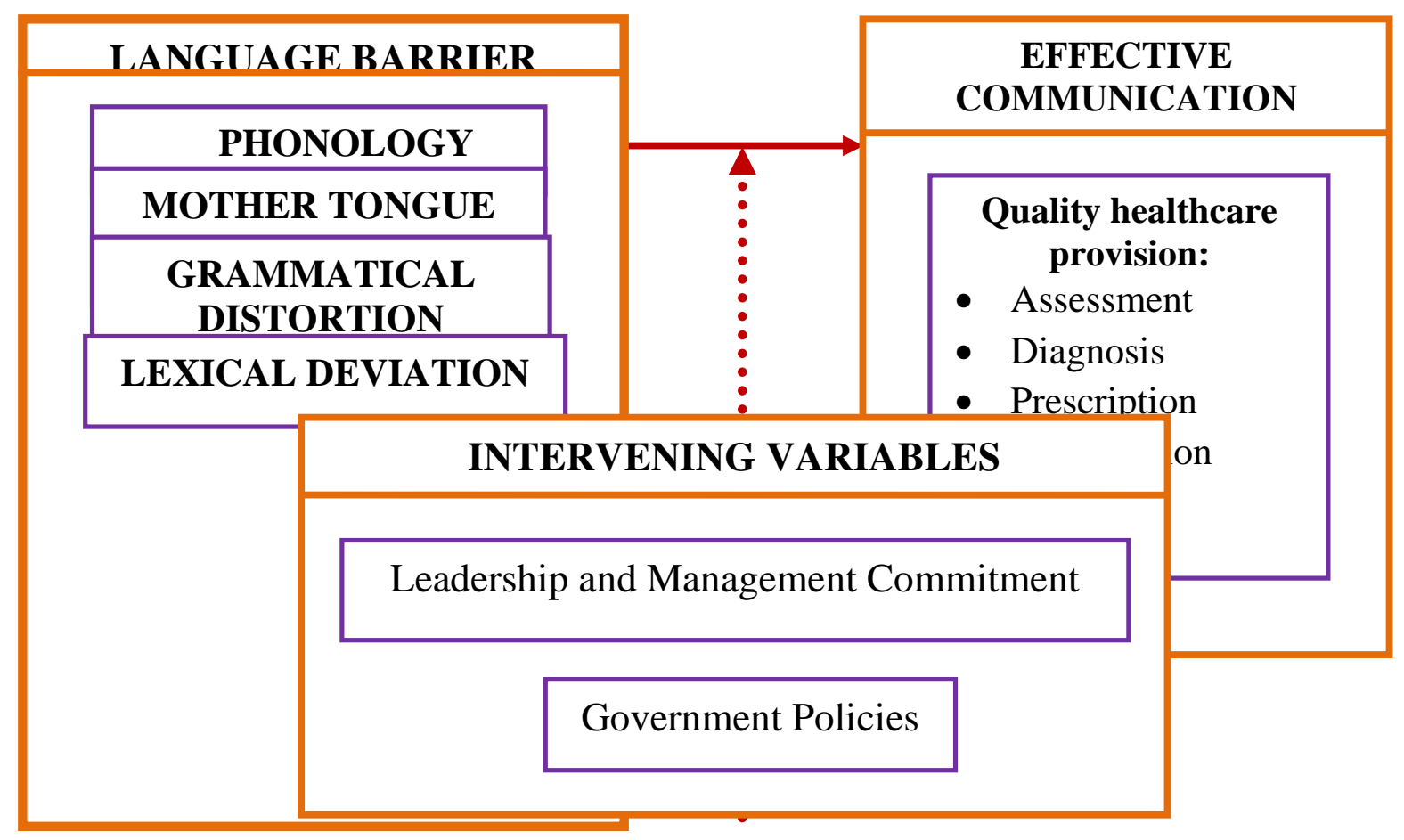

FIGURE 2.3.1: CONCEPTUAL FRAMEWORK

\section{N. 2.4Summary and Research Gap}

The literature reviewed on phonology, mother tongue interference, grammatical distortion, and lexical deviation showed that they generally affect effective communication particularly during the provision of quality health care in particular. Language barriers in some cases resulted in serious injury to patients and even in death (Ali \& Watson, 2018; Anne-Marie et al. 2013).LEP patients in most instances rarely attend medical checkups or medical counseling or testing for cases like (STI / HIV), as a result they are barred from accessing specialized services.

Despite the existing reviewed literature most of the studies were done in developed countries with a more developed communication system compared to those in Kenya. Further, these studies were done in areas with different characteristics from those of Kericho County. This study sought to bridge this gap and provide quality health care in the county. 


\section{Chapter Three}

\section{RESEARCH METHODOLOGY}

\section{A. 3.0 Introduction}

The section covers the following areas: research design, target population, instrumentation, reliability and validity of the instruments, sample size and sample procedures.

\section{B. 3.1 Research Design}

This is a case study which Kothari (2005) defines as a method that entails a cautious way to entirely examine the existing fact or an entity such as a person, a family, an institution, a cultural group or an entire community. The researcher used a mixed approach; both qualitative and quantitative. It is the most flexible of all research designs.

\section{3.2 Target Population}

The researcher targeted all health facilities in Kericho County. The county has a total of 136 health facilities with an aggregate of 2,406 health workers whose targeted population by Sub County is shown in the table below:

a) Table 3.1: Distribution of the target population by Sub-County

\begin{tabular}{lllll}
\hline Sub-County & $\begin{array}{l}\text { Health } \\
\text { Facilities }\end{array}$ & $\begin{array}{l}\text { Health } \\
\text { Facilities } \mathbf{( \% )}\end{array}$ & $\begin{array}{l}\text { Health } \\
\text { Workers }\end{array}$ & $\begin{array}{l}\text { Health } \\
\text { Workers }(\boldsymbol{\%})\end{array}$ \\
\hline Ainamoi & 20 & 14.7 & 322 & 13.4 \\
Belgut & 19 & 14.0 & 230 & 9.6 \\
Sigowet/Soin & 29 & 21.3 & 370 & 15.4 \\
Kipkelion West & 20 & 14.7 & 450 & 18.7 \\
Kipkelion East & 20 & 14.7 & 388 & 16.1 \\
Bureti & 28 & 20.6 & 646 & 26.8 \\
\hline Total & $\mathbf{1 3 6}$ & $\mathbf{1 0 0}$ & $\mathbf{2 4 0 6}$ & $\mathbf{1 0 0}$ \\
\hline
\end{tabular}

Source: Kericho County Health Department (2019)

\section{3.3 Data Collection (Instrumentation)}

In this research, data collection was done using questionnaires and structured interviews to enable the researcher to get qualitative and quantitative data.

\section{1) 3.3.1 Questionnaires}

Questionnaires were used as principal data collection instruments. The reasons the researcher chose to use them are that they can be mailed to a large number of people. However, using them can be disadvantageous in that, questions that are unclear or ambiguous may not be clarified; also, the respondent may have no opportunity to respond orally to the questions and/or issues under study. This tool provided for personal ideas (Oso \& Onen, 2008). It targeted health care workers (doctors, clinical officers, nurses, and the support staff). 


\subsubsection{Structured Interview Schedules}

Structured interview schedules were used to obtain in-depth data which was not possible to obtain using questionnaires. For instance, effective communication in the process of quality service delivery in the health facilities is best achieved from the clients' perspective because they are the real beneficiaries of the service. This may not be captured in details in the questionnaires and can best be addressed through structured interview schedules, which also assisted the researcher to explain the nature and purpose of investigation and clarify questions to the respondents. It has an advantage in that it is comprehensive and systematic. The data collected using the interview schedule can also be quantified. This helped achieve objectivity in this research. The researcher also took notes. The structure interview schedule was used to obtain data from patients visiting health facilities under study.

\section{E. Instruments}

\section{1) 3.4.1 Reliability}

It is a measure of the degree of consistency of the results obtained from a test (Kombo \& Tromp, 2007). Reliability of research instruments can be ensured by subjecting them to a pilot study excluding five selected health facilities. Selected health personnel were issued with sets of questionnaires at a given period of time. The data obtained was then analyzed and results compared. Computation was done using Chronch's alpha (KR 20) formula. Its reliability index was found to be more than 0.7 which is higher than the Cronbach Alpha $(\alpha)$ minimum value of 0.7 considered appropriate for Likert scale questions ( Mohsen \& Reg, 2011).

\subsubsection{Validity}

Validity shows how well or consistent a research instrument measures data obtained from a survey or a study, even after repeated trials and tests. (Bryman,2012). Validity of an instrument is acceptable if it produces consistent data (Nachimias, 2008).Triangulation was used in validating the research instruments as it is good in showing concurrent validity of qualitative and quantitative data (Cohen et al., 2000). Questionnaires and interviews were used in this study.

The validity of the instruments was proved by use of randomization procedures in selecting the sample for study. This helped to eliminate any bias and thus gave all the responses reflected the true image of the targeted population. The pilot study that was also conducted further assisted in guaranteeing instruments validity.

\section{F. Sampling Procedure}

\section{1) 3.5.1 Sampling Technique}

A combined process of isolating the population to be investigated as well as approximating the sample size, choosing the suitable sampling strategy and picking a study sample is called sampling technique. The procedure should be made such that error of estimation is minimized as much as possible and the fractional part selected provides only an estimate of the population characteristics (Yogesh, 2006). To reach a desired sample size, the Yamane's model $n=\frac{N}{1+N(e)^{2}}$ was used (Yamane, 1967). 
In the model $\mathrm{n}$ is the desired ample size; $\mathrm{N}$ is the population size; and e is the level of precision. At 5\% precision level, the sampled number of hospitals was $\frac{136}{1+136(0.05)^{2}} \approx 100$ while the sampled number of health workers was $\frac{2406}{1+2406(0.05)^{2}} \approx 342$

The study adopted two stage sampling technique. At first stage, a sample of 100 hospitals was randomly selected from the County. The number of health facilities which were sampled per sub-county was proportionately selected in each of the subcounties. At the second stage, a sample of 342 healthcare staff was purposely selected from the pre-selected hospitals. From each hospital, at least two staff were selected from either the department of doctors, nurses or clinical officers but this was dependent on the number of staff in the hospital. The method was deemed adequate because of its cost effectiveness and use of inferential mode of analysis whose results can be inferred on the population under investigation .The sample distribution was as indicated in the table below:

a) Table 3.2: Distribution of the sample size by Sub-County

\begin{tabular}{lllll}
\hline Sub-County & $\begin{array}{l}\text { Health } \\
\text { Facilities }\end{array}$ & $\begin{array}{l}\text { Health } \\
\text { Facilities (\%) }\end{array}$ & $\begin{array}{l}\text { Health } \\
\text { Workers }\end{array}$ & $\begin{array}{l}\text { Health } \\
\text { Workers (\%) }\end{array}$ \\
\hline Ainamoi & 15 & 14.7 & 46 & 13.4 \\
Belgut & 14 & 14.0 & 33 & 9.6 \\
Sigowet/Soin & 21 & 21.3 & 53 & 15.4 \\
Kipkelion West & 14 & 14.7 & 64 & 18.7 \\
Kipkelion East & 15 & 14.7 & 55 & 16.1 \\
Bureti & 21 & 20.6 & 91 & 26.8 \\
\hline Total & $\mathbf{1 0 0}$ & $\mathbf{1 0 0}$ & $\mathbf{3 4 2}$ & $\mathbf{1 0 0}$ \\
\hline
\end{tabular}

\section{Source: Kericho County Health Department (2019)}

\section{G. 3.6 Data Analysis}

Data analysis is the process of investigating the information gathered during the data collection process making deductions and inferences. The data analysis process constitutes bringing order to data (Yogesh, 2006).

The researcher initially edited the data collected. This assisted in removing mistakes committed by the respondents in totality. It also assisted in examining if all questions were responded to truthfully. The researcher employed the use of both descriptive and inferential statistics in the data analysis. The data was analyzed using Ms Excel and Statistical Package for Social Science (SPSS) version 21.The research hypotheses were analyzed using correlation and regression analysis. Descriptive statistics was used to analyze demographic characteristics while inferential statistics was used to analyze data on language barrier on quality of health 
care provision. The descriptive statistics made use of frequencies, percentages, mean, standard deviation, skewness and kurtosis.

The results were presented in properly interpreted tables to bring out clarity and consistency.

Objectives one to three were analyzed through models to assess language barriers effect on quality healthcare provision. This was necessary to obtain regression coefficients that estimate change in quality healthcare provision attributed change in each of the language barriers measurements. The linear regression model was:

$$
Y=\beta_{0}+\beta_{1} X+\varepsilon
$$

In model 3.1, $Y$ is effective communication during the provision of quality healthcare while $X$ stands for the respective language barrier measurements; namely, phonology, mother-tongue interference, grammatical distortion, and lexical deviation. The term $\varepsilon$ represents the divergence in quality healthcare provision from that estimated by determined constants. The error terms were assumed to have a normal distribution with variance $\sigma^{2}$. The results were presented in tables with clear interpretations.

\section{H. 3.7 Ethical Considerations}

It is defined as that behavior that conforms to standards or conducts of a given profession or group. In this study the researcher engaged the participants voluntarily and confidentiality of the respondents was assured. It was further ensured that they suffered no harm from the research procedures. Numbers replaced names of respondents in the data collection forms so that not even the researcher could link the data collected to a particular respondent, however, where individual respondent were identified, their confidentiality wasguarded. An approval from Mt. Kenya University, School of Postgraduate Studies was given. A research permit was obtained from NACOSTI as attached.

\section{Chapter Four}

\section{ReSEARCh Findings, ANALYSIS AND Presentation}

VIII.

\section{A. 4.0 Introduction}

In this chapter, the results of the study are presented and discussed. The analysis of variables was done through descriptive and inferential statistics. Descriptive analysis was done through frequencies, percentages, means, standard deviations, kurtosis and skewness while inferential analysis was done through linear regression equations. In particular, the chapter presents results on response rate; demographic characterizations and language barrier measurements affecting the provision of quality healthcare.

\section{B. 4.1 Response Rate}

This section presents data on staff participation in the study. The table below presents data on staff participation in the study.

a) Table 4.1: Response Rate

$\begin{array}{lll}\text { Categories } & \text { Healthcare Staff (Doctors, Nurses, } & \text { Healthcare Staff (Doctors, Nurses, } \\ & \text { Clinical Officers) } & \text { Clinical Officers }(\%)\end{array}$




\begin{tabular}{llc}
\hline Response & 296 & 86.55 \\
None Response & 46 & 13.45 \\
Total & 342 & 100 \\
\hline
\end{tabular}

Source: Survey data (2019)

Table 4.1 shows that out of 342 questionnaires given out, $86.55 \%$ (296) were filled and returned, the non-response accounted for $13.45 \%$ (46). The response rate was adequate to provide accurate results since Mugenda and Mugenda (2003) recommends a 50\% minimum asadequate for data analysis.

\section{4.2 Demographic Characterization}

This section presents data on healthcare staff:gender, age, education level, professional specialization, and years of service in the health sector.

\subsubsection{Staff Gender}

The researcher sought information on the distribution of the respondents (healthcare staff) by gender,to find out if the health facility survey were gender sensitive, thus recognizing their roles in the provision of healthcare services. The details are provided in table 4.2 .

a) Table 4.2: Gender distribution of the Healthcare Staff

\begin{tabular}{ccc}
\hline Category & Healthcare staff & Healthcare staff $(\%)$ \\
\hline Male & 139 & 47.0 \\
Female & 157 & 53.0 \\
Total & $\mathbf{2 9 6}$ & $\mathbf{1 0 0 . 0}$ \\
\hline
\end{tabular}

Source: Survey data (2019)

In the table shown above, out of the 296 healthcare staff involved in the study, $47.0 \%$ (139) were males while, 53.0\% (157) females. This indicates that there was almost no gender parity in those who took part in the study. The health facilities understand the roles of both gender in their operations.

\subsubsection{Age of Healthcare staff}

The researcher further sought information $\mathrm{n}$ the age of the staff. Age is thus key in understanding the mental maturity in conceptualizing and responding to the question items. See table below:

b) Table 4.3: Age of the Healthcare Staff 


\begin{tabular}{lll}
\hline Age Category & Healthcare Staff & Healthcare Staff $(\%)$ \\
\hline$<20$ & 0 & 0.0 \\
$20-29$ & 55 & 18.6 \\
$30-39$ & 105 & 35.5 \\
$40-49$ & 98 & 33.1 \\
$>49$ & 38 & 12.8 \\
Total & $\mathbf{2 9 6}$ & $\mathbf{1 0 0 . 0}$ \\
\hline
\end{tabular}

Source: Survey data (2019)

The above table shows that all respondents were above 20 years of age with (87.2\%) aged between 20 and 50 years while $12.8 \%$ (38) were above 50 years. Thus a bigger percentage of the healthcare staff was in an active age and could adequately and quickly respond to items in the questionnaire.

\subsubsection{Educational level of the healthcare staff}

In this sub-section, data on educational level was sought which included secondary, tertiary and university levels. This was necessary for intellectual capability of respondents in responding to questionnaire items. The details are as follows:

c) Table 4.4:Level of formal education

\begin{tabular}{lll}
\hline Levels & Healthcare Staff & Healthcare Staff (\%) \\
\hline Secondary & 0 & 0.0 \\
Tertiary & 182 & 61.5 \\
University & 114 & 38.5 \\
Total & $\mathbf{2 9 6}$ & $\mathbf{1 0 0 . 0}$ \\
\hline
\end{tabular}

Source: Survey data (2019)

In the table above, out of the 296 healthcare staff who participated in the study, none had secondary level of education. Majority $(61.5 \%)$ had tertiary level, while $38.5 \%$ (114) had university education. This shows that a significant proportion of the staff had good qualifications and could respond adequately to the items in the questionnaire.

\subsubsection{Staff Specialization}

This sub-section provides data on the specialities of the respondents, in the health facility. This was sought to understand the level of interaction between the staff and the clients in responding to questionnaire items as shown in the findings below:

d) Table 4.5: Professional Specialization

\begin{tabular}{ccc}
\hline Category & Healthcare Staff & Healthcare Staff (\%) \\
\hline Doctors & 26 & 8.8 \\
& & \\
\hline
\end{tabular}




$\begin{array}{lcc}\text { Nurses } & 136 & 45.9 \\ \text { Clinical Officers } & 105 & 35.5 \\ \text { Others } & 29 & 9.8 \\ \text { Total } & \mathbf{2 9 6} & \mathbf{1 0 0 . 0}\end{array}$

Source: Survey data (2019)

It indicates that 296 respondents participated in the study. 8.8\% (260) doctors, $45.9 \%$ (136) nurses, 35.5\% (105) clinical officers while others (nutritionists, counsellors) were $9.8 \%$ (29). The respondents consisted of a variety of professionals with varied knowledge, experience and skills in relation to the operations of the health facilities and could adequately respond to the items in the questionnaire.

\subsubsection{Duration of service in the health sector}

Respondent's length in service in health practice was sought. This was necessary in gauging their understanding of the effect of language barrier on provision of quality healthcare. The findings are presented in the table below:

e) Table 4.6: Duration in the Health Facility

\begin{tabular}{lll}
\hline Duration (Years) & Health Staff & Health Staff $(\%)$ \\
\hline$<5$ & 44 & 14.9 \\
$5-9$ & 88 & 29.7 \\
$10-14$ & 82 & 27.7 \\
$15-19$ & 56 & 18.9 \\
$\geq 20$ & 26 & 8.8 \\
Total & $\mathbf{2 9 6}$ & $\mathbf{1 0 0 . 0}$ \\
\hline
\end{tabular}

Source: Survey data (2019)

In this table,296 health workers participated in the study. Out of these 14.4\% (44) had been in service for less than 5 years while $85.1 \%$ (252) had served for more than five years. The distribution showed that a bigger proportion of the healthcare staff had been in service for some time and therefore had adequate knowledge on the effect of language barrier on the provision of quality healthcare services.

\section{4.3 Effect of Language Barrier on Quality Healthcare Provision}

The section presents an empirical analysis of the effect of language barrier on quality healthcare provision. It particularly analyzed the effect of phonology, mother-tongue interference, grammatical distortion, and lexical deviation on effective communication for the provision of quality healthcare in these facilities. 


\subsubsection{Effect of phonology on effective communication for the provision of quality healthcare}

This part presents an analysis and interpretation of the effect of phonology on effective communication for the provision of quality healthcare services. It reveals descriptive statistics showing valid data item percentages, skewness, kurtosis, means and standard deviations for each variable. The results are as shown in table 4.7.

a) Table 4.7: Descriptive information on phonology and provision of quality healthcare

\begin{tabular}{|c|c|c|c|c|c|c|c|c|c|c|}
\hline Constructs & & $\mathbf{S A}$ & $\overline{\mathbf{A}}$ & $\mathbf{N}$ & $\mathbf{D}$ & SD & Ske & Kur & Mean & S.D \\
\hline $\begin{array}{l}\text { Phonology affects assessment } \\
\text { during healthcare }\end{array}$ & $\begin{array}{l}\mathrm{f} \\
\%\end{array}$ & $\begin{array}{l}122 \\
41.2\end{array}$ & $\begin{array}{l}145 \\
49.0\end{array}$ & $\begin{array}{l}29 \\
9.8\end{array}$ & $\begin{array}{l}0 \\
0.0\end{array}$ & $\begin{array}{l}0 \\
0.0\end{array}$ & -0.4 & -0.7 & 4.31 & 0.64 \\
\hline Phonology affects diagnosis during & $\mathrm{f}$ & 142 & 109 & 45 & 0 & 0 & -0.6 & -0.9 & 4.33 & 0.73 \\
\hline healthcare & $\%$ & 48.0 & 36.8 & 15.2 & 0.0 & 0.0 & & & & \\
\hline prescription & $\mathrm{f}$ & 59 & 48 & 8 & 103 & 78 & 0.4 & -1.4 & 2.69 & 1.51 \\
\hline during healthcare & $\%$ & 19.9 & 16.2 & 2.7 & 34.8 & 26.4 & & & & \\
\hline dispensation & $\mathrm{f}$ & 36 & 66 & 6 & 99 & 89 & 0.5 & -1.2 & 2.53 & 1.43 \\
\hline during healthcare & $\%$ & 12.2 & 22.3 & 2.0 & 33.4 & 30.1 & & & & \\
\hline Overall aggregated mean & & & & & & & & & 3.47 & 1.08 \\
\hline
\end{tabular}

Key: SA-Strongly agree, A-Agree, N-Neutral, D-Disagree, SD-Strongly disagree, Ske- Skewness, Kur-Kurtosis, S.DStandard deviation

Source: Survey data (2019)

In the above table, all respondents; $41.2 \%$ (122) and 49.0\% (145) strongly agreed and agreed respectively that 'phonology affects assessment of medical conditions during the provision of quality healthcare'. $9.8 \%(29)$ remained neutral concerning the effect phonology on efffective communication during the provision of quality healthcare.48.0\% (142) and 36.8\% (109) of strongly agreed and agreed in that order that 'phonology on effective communication affect diagnosis of medical condition during the provision of quality healthcare'. 15.2\% (45) however, remained neutral on this matter. The mean response on this statement was 4.33 with S.D of 0.73 .

Similarly, a majority of the respondents- $61.2 \%$ (34.8\% disagreed and $26.4 \%$ strongly disagreed)generally disagreed with the statement that; " Phonology affectseffective communication in prescription of medical drugs during the provision of quality healthcare". However, $19.9 \%$ (59) strongly agreed and $16.2 \%$ (48) agreed with $2.7 \%$ (8) remaining neutral on the statement. The study generaly revealed an overwhelming disagreement (mean $=2.69, \mathrm{SD}=1.51)$. The respondents generally felt that phonology 
did not affect effective communication in dispensation of medical drugs during the provision of quality healthcare $($ mean $=2.53$ and S.D $=1.43)$. Of the respondents that took part in the study, only $34.5 \%(12.2 \%$ strongly agreed and $22.3 \%$ agreed $)$ felt that phonology affected effective communication in dispensation of drugs during the provision of quality healthcare. $2.0 \%$ (6) however, remained neutral.

From table 4.7, there was a general concurrence that phonology affects effective communication in assessment of medical condition during the provision of quality healthcare (aggregate mean $=3.47$ and S.D $=1.08$ ). The values of skewness and kurtosis indicated that phonology depicted a normal distribution as the values were within the interval of -2.0 and +2.0 as recommended by Tabachnick and Fidell (2007).

Some of the patients interviewed expressed very close relationship between phonology and effective communication during provision of quality healthcare. For example;

"Some of the doctors and other hospital staff talk fast and it is difficult for me to understand what they are saying ........"(Patient 3)

"I usually strain in understanding some of the medical staff especially those from a different ethnic community.... It is hard to understand what they are saying ...

(Patient 8)

"In most cases patients repeat themselves several times following differences in ethnic accent. The medical officer has to repeat questions many times and also there seems to be a problem with understanding. . ..$"$ (Patient 18)

Linear regression analysis was further sought. The regression model explored was:

$$
Y=\beta_{0}+\beta_{1} X+\varepsilon
$$

The variable $Y$ represented effective communication during the provision of quality healthcare and the variable $X$ represented phonology in communication. The residual $\varepsilon$ represented departure of the observed values of effective communication from what the model could estimate.

Tests were initially done on model 4.1 to ascertain the relationship between adjacent residuals. The results indicated no correlation as presented in table 4.8. The Durbin-Watson statistic value was 2.331 which was within the recommended interval of 1 to 3 according to Field (2009). The results in Table 4.8 indicated significant positive correlation coefficient between phonology and effective communication $(\mathrm{R}=.627 ; \mathrm{P}<.05)$ thus qualifying linearity of the relationship.

The initial assumptions were satisfied and the effect of phonology on effective communication during the provision of quality healthcare was tested. The hypothesis that there was no statistically significant effect of phonology on effective communication 
for the provision of quality healthcare in Kericho County healthcare facilities was therefore tested at 5\% significance level. The results are presented in the table below:

b) Table 4.8: Linear regression analysis for the effect of phonology on effective communication

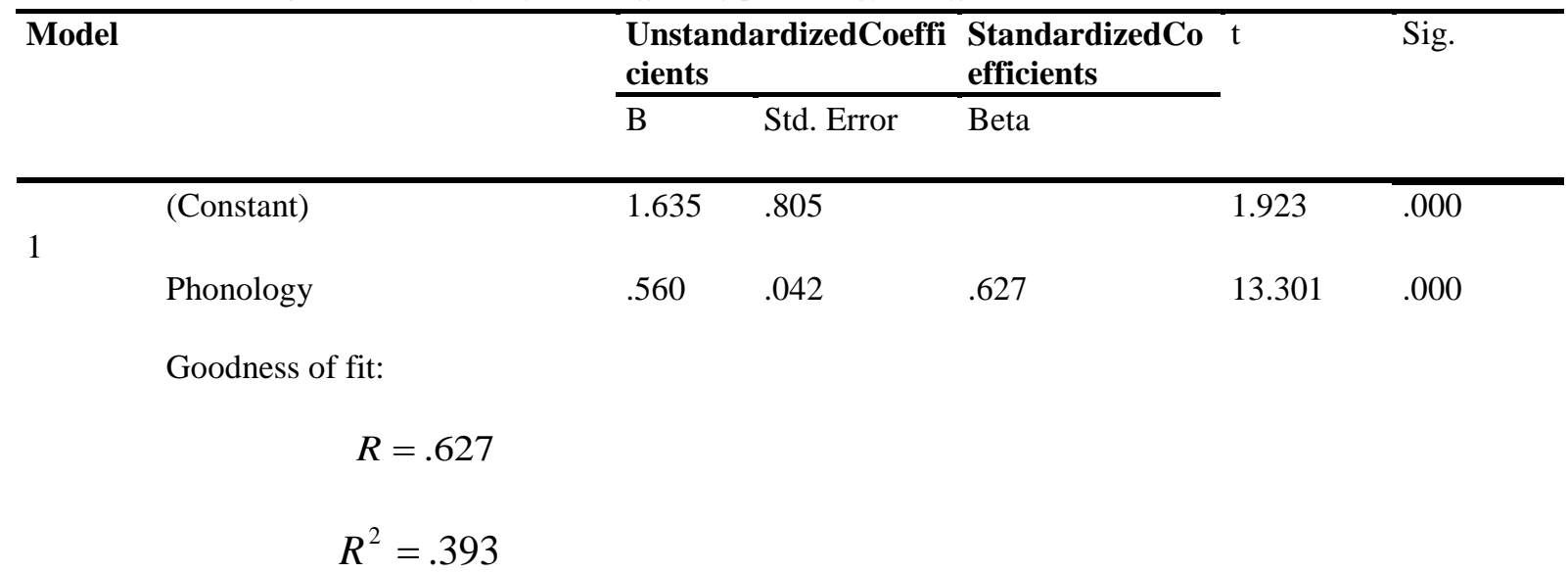

Adjusted $R^{2}=.388$

$F(1,295)=123.221$

$P<.05$

Durbin-Watson: 2.331
a. Dependent Variable: Effective communication
b. Independent Variable: Phonology

From Table 4.8, it was indicated that there was a statistically significant positive correlation $(\mathrm{R}=.627$; $\mathrm{P}<.05)$ between phonology and effective communication during the provision of quality healthcare. The portion of effective communication which was attributed to phonology was depicted by the value of R-square which was .393. This value (.393) indicated that phonology could approximately account for $39.3 \%$ of effective communication during the provision of quality healthcare.

The value of the adjusted $\mathrm{R}$ square showed that if the entire population was used instead of the study sample, then the resultant model would account for approximately $.004(.4 \%)$ less variations in the findings. The value $F_{(1,295)}=123.221 ; \mathrm{P}<.05$ affirmed that the regression model was statistically significant hence the null hypothesis was rejected. Considering the standardized beta coefficients for one positive standard deviation in phonology, effective communication during the provision of quality healthcare would be improved by approximately .625 .

\subsubsection{Effect of mother-tongue interference on effective communication for the provision of quality healthcare}


The second objective of this study was to find out the effect of mother-tongue interference on effective communication for theprovision of quality healthcare. This part analyzes and interprets the results of the objectives. The descriptive statistics showing valid data items percentages, skewness, kurtosis, means and standard deviations for each variable was analyzed.The results were as indicated in the figure 4.1 below

\section{FIGURE 4.1: COMMON LANGUAGES USED BY HEALTHCARE STAFF}

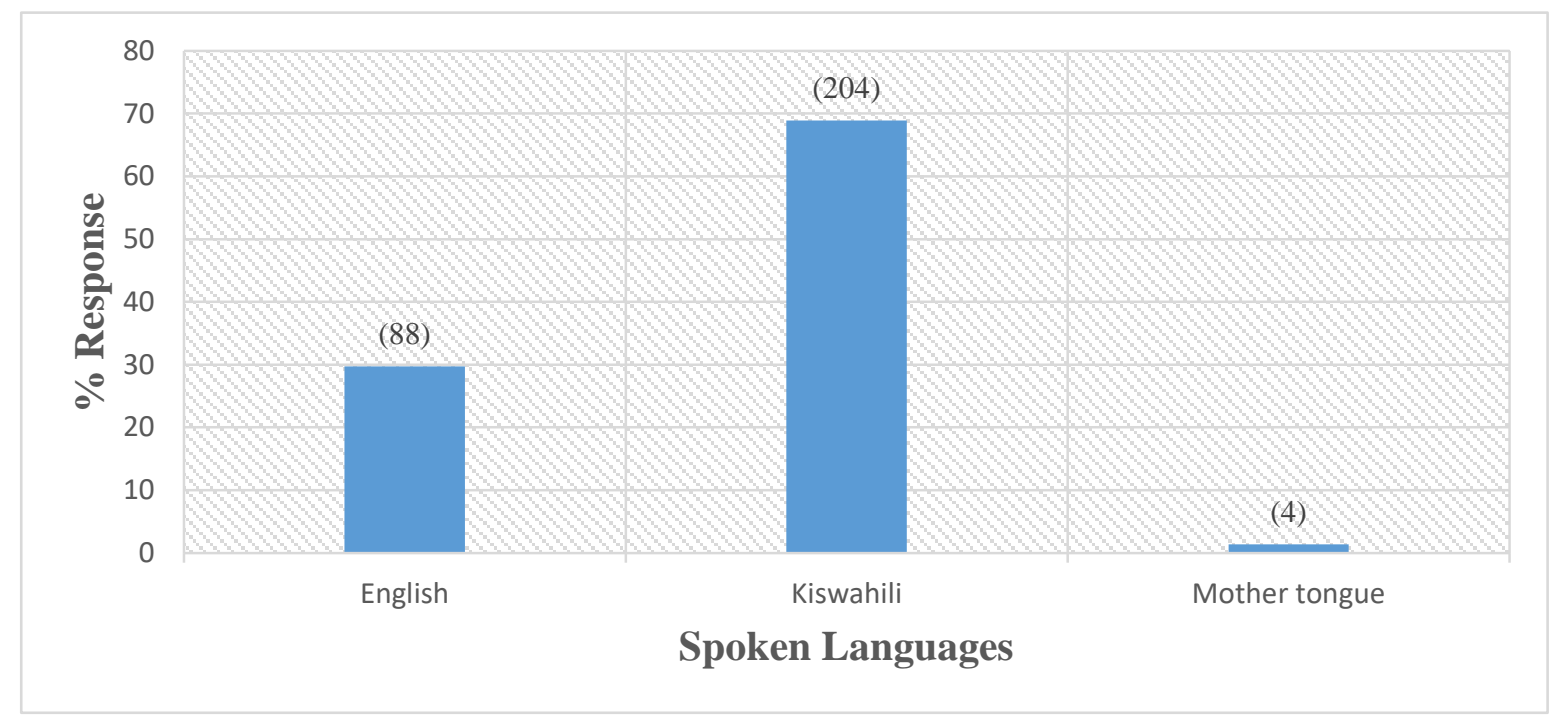

The results displayed in the figure showed that health providers used different languages in communicating with the patients in an attempt to provide quality healthcare. The results showed that the commonly used language was Kiswahili $68.9 \%$ ), followed by English (29.7) while mother-tongue came third at 1.4\%. Kiswahili could have topped the list since it was the National language of the Kenyan people, while English was the official language of the country and was not that much understood. Mother-tongue lagged behind sinceKericho County has different ethnic communities hence the use of mother-tongue in most health facilities is not popular.

With the help of a likert scale, the respondents were asked to indicate to indicate the level in which they agreed or disagreed with the statements with regard to the effect of mother-tongue interference on the provision of quality healthcare services in the facilities. Likert scale was coded as follows: Strongly Agree was rated 5, Agree-4, Neutral- 3, Disagree - 2 and Strongly Disagree-

1. The results are shown in table 4.9.

c) Table 4.9: Descriptive information on mother-tongue interference and provision of quality healthcare

\begin{tabular}{|c|c|c|c|c|c|c|c|c|c|c|}
\hline Constructs & & SA & $\mathbf{A}$ & $\mathbf{N}$ & $\mathbf{D}$ & SD & Ske & Kur & Mean & S.D \\
\hline Mother-tongue interference affects & $\mathrm{f}$ & 166 & 130 & 0 & 0 & 0 & -0.4 & -0.7 & 4.31 & 0.64 \\
\hline assessment during healthcare & $\%$ & 56.1 & 43.9 & 9.8 & 0.0 & 0.0 & & & & \\
\hline Mother-tongue interference affects & $\mathrm{f}$ & 78 & 82 & 9 & 127 & 0 & -0.6 & -0.9 & 4.33 & 0.73 \\
\hline
\end{tabular}




\begin{tabular}{|c|c|c|c|c|c|c|c|c|c|c|}
\hline diagnosis during healthcare & $\%$ & 26.4 & 27.7 & 3.0 & 42.9 & 0.0 & & & & \\
\hline Mother-tongue interference affects & $\mathrm{f}$ & 100 & 174 & 0 & 22 & 0 & 0.4 & -1.4 & 2.69 & 1.51 \\
\hline prescription during healthcare & $\%$ & 33.8 & 58.8 & 0.0 & 7.4 & 0.0 & & & & \\
\hline Mother-tongue interference affects & $\mathrm{f}$ & 15 & 136 & 0 & 109 & 36 & 0.5 & -1.2 & 2.53 & 1.43 \\
\hline dispensation during healthcare & $\%$ & 5.1 & 45.9 & 0.0 & 36.8 & 12.2 & & & & \\
\hline Being able to speak in the language & $\mathrm{f}$ & 165 & 131 & 0 & 0 & 0 & -0.2 & -2.0 & 4.55 & 0.49 \\
\hline attendance & $\%$ & 55.7 & 44.3 & 0.0 & 0.0 & 0.0 & & & & \\
\hline Overall aggregated mean & & & & & & & & & 3.68 & 0.96 \\
\hline
\end{tabular}

Key: SA-Strongly agree, A-Agree, Un-Undecided, D-Disagree, SD-Strongly disagree, Ske- Skewness, Kur-Kurtosis, S.DStandard deviation

Table 4.9 revealed that the respondents overwelmingly agreed $100 \%$ (mean $=4.31$ and S.D 0.64 ) that the: 'mother-tongue interference affect assessment of medical conditions during the provision of quality healthcare'. In particular, 56.1\% (166) strongly agreed while $43.9 \%$ (130) agreed with the statement.

According to this study there was mixed opinion with respect to the effect of mother-tongue interference on effective communication in diagnosis of medical conditions. $26.4 \%$ (78) strongly agreed, and $27.7 \%$ (82) agreed that mother-tongue affects effective communication. This composed of slightly more than half (160) of all the respondents. Out of this, 3.0\% (9) were neutral with 42.9 (127)disagreeing with the statement. The mean response on this item was 4.33 and SD was 0.73 indicating that majority of respondents were in agreement that mother-tongue interference affected effective communication in diagnosis of medical conditions.

From table 4.9, there was a general agreement that mother-tongue interference affected effective communication in provision of quality healthcare (aggregate mean $=3.47$ and S.D $=1.08) .92 .6 \%(274)$ of the respondents felt that it affects communication in prescription of medical drugs during the provision of quality healthcare which was represented by $100(33.8 \%)$ and $102(31.0 \%)$ of the respondents disagreeing and strongly disagreeing with the statement respectively. Only $33.4 \%$ had confidence in the leadership qualities of the health facilities.

The study generally revealed that mother-tongue interference on effective communication did not affect dispensation of medical drugs during the provision of quality healthcare (mean $=2.53$ and S.D $=1.43$ ). Specifically, only $5.1 \%(15)$ and $45.9 \%(136)$ of the respondents strongly agreed and agreed respectively with this questionnaire item. 36.8\% (109) and 12.2\% (36) disagreed and strongly disagreed respectively. 
The importance of health providers' ability to speak and understand the language of the patient got majority endorsement with a mean of 4.55 and SD of 0.49 . This result indicated that due to the use of a language that could be understood by both patient and health providers, interaction between the two parties is enhanced, thus encouraging patient attendance. Qualitative data from some of the patients interviewed affirmed these findings. They asserted that:

"Sometimes am not sure if the medical officer understands me. He/she keeps on repeating one question several times only to realize later that he is not from my tribe and does not understand my mother-tongue....” (Patient 23)

"It is not easy to explain some issues in either English or Kiswahili, and I often resort to mother-tongue to explain myself better..." (Patient 30)

Qualitative data from other patients however indicated different opinions concerning mother-tongue interference on effective communication for provision of quality healthcare. One of the patients reported that:

“It does not matter even if I can't express myself fluently in either English or Kiswahili....I use sign language or an interpreter when the medical officer cannot understand me.... ." (Patient 34)

"Using an interpreter is not an option for... There are issues which are much confidential and are meant only for the medical officers. Even if it means using my mother-tongue in expressing myself....." (Patient 35)

From table 4.9, there was a general concurrence that mother-tongue interference affected effective communication in assessment of medical condition during the provision of quality healthcare (aggregate mean $=3.68$ and S.D $=0.96$ )

The values of skewness and kurtosis indicated that phonology depicted a normal distribution as the values were within the interval of -2.0 and +2.0 recommended by Tabachnickand Fidell (2007).

Linear regression analysis was further sought. The regression model explored was:

$$
Y=\beta_{0}+\beta_{1} X+\varepsilon
$$

The variable $Y$ represented effective communication during the provision of quality healthcare and the variable $X$ represented mother-tongue interference in communication. The residual $\varepsilon$ represented departure of the observed values of effective communication from what the model could estimate. Tests were initially done on model 4.2 to ascertain the relationship between adjacent residuals. The results indicated no correlation as presented in table 4.10. The Durbin-Watson statistic value was 1.880 which was with the recommended interval of 1 to 3 according to Field (2009). The results in Table 4.10indicated statistically significant positive correlation coefficient between mother-tongue interference and effective communication $(\mathrm{R}=.524$; $\mathrm{P}<.05)$ qualifying linearity of the relationship. 
The initial assumptions were satisfied, and the effect of mother-tongue interference in effective communication during the provision of quality healthcare was thus tested. The hypothesis that there is no statistically significant effect of mother-tongue interference on effective communication for the provision of quality healthcare in Kericho County health facilities, Kenya was therefore tested at 5\% significance level. The results are presented in table 4.10.

d) Table 4.10: Linear regression analysis for the influence of leadership on performance

\begin{tabular}{|c|c|c|c|c|c|}
\hline \multirow[t]{2}{*}{ Model } & \multicolumn{2}{|c|}{$\begin{array}{l}\text { Unstandardized } \\
\text { Coefficients }\end{array}$} & \multirow[t]{2}{*}{$\begin{array}{l}\text { Standardized } \\
\text { Coefficients }\end{array}$} & \multirow[t]{2}{*}{$\bar{t}$} & \multirow[t]{2}{*}{ Sig. } \\
\hline & $\mathrm{B}$ & Std. Error & & & \\
\hline (Constant) & 1.226 & .176 & & 6.901 & .000 \\
\hline Mother-tongue inter & .865 & .064 & -.524 & 13.415 & .000 \\
\hline
\end{tabular}

$$
\begin{aligned}
R & =.524 \\
R^{2} & =.275
\end{aligned}
$$

Adjusted $R^{2}=.273$

$F(1,295)=101.360$

$P<.05$

Durbin-Watson:1.880

a. Dependent Variable: Academic performance

b. Independent Variable: Leadership

Source: Survey data (2019)

From Table 4.10, it was indicated that there was a statistically significant negative correlation $(\mathrm{R}=.524 ; \mathrm{P}<.05)$ between mothertongue interference and effective communication during the provision of quality healthcare. The portion of effective communication which was attributed to mother-tongue interference was depicted by the value of R-square which was .275. The value of R-square (.275) indicated that mother-tongue interference could approximately account for only $27.5 \%$ of effective communication during the provision of quality healthcare. The value of the adjusted R square showed that if the entire population was used instead of the study sample, then the resultant model would account for approximately .002 (.2\%) less variations in the findings. The value $F_{(1,295)}=101.360 ; \mathrm{P}<.05$ affirmed that the regression model was statistically significant hence the null hypothesis was rejected.

Considering the standardized beta coefficients, for one positive standard deviation in mother-tongue interference, effective communication during the provision of quality healthcare would be reduced by approximately .524 effectiveness. 


\subsubsection{Effect of grammatical distortion on effective communication for the provision of quality healthcare}

In this case, the third objective of the study; which was to determine the effect of grammatical distortion on effective communication for the provision of quality healthcare is analyzed and interpreted. The descriptive statistics showing valid data items percentages, skewness, kurtosis, means and standard deviations for each variable is analyzed. The researchers requested that the respondents with the help of likert scale to indicate the level in which they agreed or disagreed with statements on the effect of grammatical distortion on effective communication for the provision of quality healthcare. Likert scale was coded such that:

Strongly Agree rated 5, Agree-4, Neutral- 3, Disagree - 2, and Strongly Disagree-1.

The results are shown in table 4.11 below.

e) Table 4.11: Descriptive information on grammatical distortionon provision of quality healthcare

\begin{tabular}{|c|c|c|c|c|c|c|c|c|c|c|}
\hline Constructs & & $\mathbf{S A}$ & $\mathbf{A}$ & $\mathbf{N}$ & $\mathbf{D}$ & SD & Ske & Kur & Mean & S.D \\
\hline Grammatical distortion affects & $\mathrm{f}$ & 0 & 0 & 33 & 110 & 153 & 0.7 & -0.6 & 1.60 & 0.68 \\
\hline assessment during healthcare & $\%$ & 0.0 & 0.0 & 11.1 & 37.2 & 51.7 & & & & \\
\hline Grammatical distortion affects & $\mathrm{f}$ & 0 & 23 & 44 & 122 & 107 & 0.7 & -0.2 & 1.94 & 0.91 \\
\hline diagnosis during healthcare & $\%$ & 0.0 & 7.8 & 14.9 & 41.2 & 36.1 & & & & \\
\hline Grammatical distortion & $\mathrm{f}$ & 22 & 55 & 0 & 132 & 87 & 0.8 & -0.6 & 2.30 & 1.27 \\
\hline prescription during healthcare & $\%$ & 7.4 & 18.6 & 0.0 & 44.6 & 29.4 & & & & \\
\hline Grammatical distortion affects & $\mathrm{f}$ & 0 & 0 & 11 & 109 & 176 & 0.8 & -0.3 & 1.44 & 0.57 \\
\hline dispensation during healthcare & $\%$ & 0.0 & 0.0 & 3.7 & 36.8 & 59.5 & & & & \\
\hline Overall aggregated mean & & & & & & & & & 1.82 & 0.86 \\
\hline
\end{tabular}

Key: SA-Strongly agree, A-Agree, Un-Undecided, D-Disagree, SD-Strongly disagree, Ske- Skewness, Kur-Kurtosis, S.D-

\section{Standard deviation}

Source: Survey data (2019)

From Table 4.11 , majority $(88.9 \%)$ of the respondents were of the opinion that grammatical distortion did not affect effective communication in assessment of medical conditions during 
It was evidently revealed that grammatical distortion did not affect effective communication in diagnosis of medical conditions during the provision of quality healthcare as was depicted by majority $(77.3 \%$ ) of the respondents (made of $41.2 \%$ and $36.1 \%$ of those who disagreed and strongly disagreed respectively). Only 7.8\% (23) agreed that grammatical distortion affected effective communication in diagnosis of medical conditions during the provision of quality healthcare while $14.9 \%$ (44) remained neutral on this matter.

This study further indicated that $7.4 \%$ (22) and $18.6 \%$ (55) of the repondents strongly agreed and agreed respectively with the statement that 'gramatical distortion affects communicationin prescription of medical drugs during the provision of quality healthcare'. Majority (44.6\%) and 29.4\% (87) disagreed and strongly disagreed with the statement. Mean response was 2.30 with a S.D of 1.27 .

Finally, majority $(96.3 \%)$ of the respondents indicated that grammatical distortion indicated that grammatical distortion did not affect effective communication in dispensation of medical drugs. This constituted of 36.8\% (109) and 59.5\% (176) of those who disagreed and strongly disagreed respectively with the statement. 3.7\% (11) of the respondents however, remained neutral on the matter. The mean response was 1.44 with a S.D of 0.57 . Qualitative data from the patients affirmed these findings. It was asserted by five different patients that:

Grammar in communication is very important especially when English language is involved. However, so long as the medical staff can connect and understand me....grammatical distortion is of no importance. (Patient $8,12,17,25 \& 27$ ) Linear regression analysis was further sought. The regression model explored was:

$$
Y=\beta_{0}+\beta_{1} X+\varepsilon
$$

The variable $Y$ represented effective communication during the provision of quality healthcare and the variable $X$ represented grammatical distortion in communication. Theresidual $\varepsilon$ represented departure of the observed values of effective communication from what the model could estimate.

Tests were initially done on model 4.3 to ascertain the relationship between adjacent residuals. The results indicated no correlation as presented in table 4.12. The Durbin-Watson statistic value was 1.534 which was with the recommended interval of 1 to 3 according to Field (2009). The results in Table 4.12indicated a statistically significant positive correlation coefficient between grammatical distortion and effective communication $(\mathrm{R}=.524 ; \mathrm{P}<.05)$ qualifying linearity of the relationship. The initial assumptions were satisfied, and the effect of grammatical distortion in effective communication during the provision of quality healthcare was thus tested.The hypothesis that there is no statistically significant effect of grammatical distortion in effective communication for the provision of quality healthcare in the facilities was therefore tested at 5\% significance level. The results are presented in table 4.12 . 
f) Table 4.12: Linear regression analysis for the effect of grammatical distortion on effective communication

\begin{tabular}{|c|c|c|c|c|c|}
\hline Model & \multicolumn{2}{|c|}{$\begin{array}{l}\text { Unstandardized } \\
\text { Coefficients }\end{array}$} & \multirow[t]{2}{*}{$\begin{array}{l}\text { Standardized } \\
\text { Coefficients }\end{array}$} & \multirow[t]{2}{*}{$\bar{t}$} & \multirow[t]{2}{*}{ Sig. } \\
\hline & B & Std. Error & & & \\
\hline (Constant) & 3.251 & .135 & & 24.002 & .000 \\
\hline Facilities & .533 & .046 & -.215 & 11.652 & .000 \\
\hline \multicolumn{6}{|l|}{ Goodness of fit: } \\
\hline \multicolumn{6}{|c|}{$R=.215$} \\
\hline \multicolumn{6}{|c|}{$R^{2}=.046$} \\
\hline \multicolumn{6}{|l|}{ Adjusted $R^{2}=.044$} \\
\hline \multicolumn{6}{|l|}{$F(1,295)=23.111$} \\
\hline \multicolumn{6}{|l|}{$P<.05$} \\
\hline Durbin-Watson:1.534 & & & & & \\
\hline
\end{tabular}

a. Dependent Variable: Academic performance

b. Independent Variable: Facilities

Source: Survey data (2019)

From Table 4.12, it was indicated that there was a statistically significant weak negative correlation $(\mathrm{R}=.215 ; \mathrm{P}<.05)$ between grammatical distortion and effective communication during the provision of quality healthcare. The portion of effective communication which was attributed to grammatical distortion was depicted by the value of R-square which was .046. The value of R-square (.046) indicated that grammatical distortion could approximately account for only $4.6 \%$ of effective communication during the provision of quality healthcare. The value of the adjusted $\mathrm{R}$ square showed that if the entire population was used instead of the study sample, then the resultant model would account for approximately $.002(.2 \%)$ less variations in the findings. The value $F_{(1,295)}=23.111 ; \mathrm{P}<.05$ affirmed that the regression model was statistically significant hence the null hypothesis was rejected. Considering the standardized beta-coefficients, for one positive standard deviation in grammatical distortion, effective communication during the provision of quality healthcare would be reduced by approximately .215 effectiveness.

\subsubsection{Effect of lexical deviation on effective communication for the provision of quality healthcare}

The fourth and the last objective of this study was to investigate the effect of lexical deviation on effective communication for the provision of quality healthcare in Kericho Countyhealth facilities, Kenya. The researcher achieved this objective by asking the repondents to give their opinion regarding language use in effective communication in medical conditions' assessment, diagnosis of medical condition, prescription of drugs, and dispensation of drugs during the provision of quality healthcare. The data was analyzed using frequencies, percentages, means and standard deviations (SD). Linear graphs were used in presenting the results. 
The respondents were asked by the help of likert scale to indicate the level in which they agreed or disagreed with statements on the effects of lexical deviation on effective communication for the provision of quality healthcare services in the facilities. Likert scale which was given to the respondents was such that the questionnaire responses were coded with Strongly Agree rated 5, Agree - 4, Neutral - 3, Disagree - 2 and Strongly Disagree-1. The findings are indicated in Table 4.13.

g) Table 4.13: Descriptive information on lexical deviation and provision of quality healthcare

\begin{tabular}{|c|c|c|c|c|c|c|c|c|c|c|}
\hline Constructs & & $\mathbf{S A}$ & $\bar{A}$ & $\mathbf{N}$ & $\mathbf{D}$ & SD & Ske & Kur & Mean & S.D \\
\hline Lexical deviation affects assessment & $\mathrm{f}$ & 84 & 78 & 56 & 78 & 0 & -0.5 & -1.2 & 3.31 & 1.53 \\
\hline during healthcare & $\%$ & 28.4 & 26.4 & 18.9 & 26.4 & 0.0 & & & & \\
\hline Lexical deviation affects diagnosis & $\mathrm{f}$ & 99 & 111 & 0 & 86 & 0 & -0.5 & -1.3 & 3.75 & 1.20 \\
\hline during healthcare & $\%$ & 33.4 & 37.5 & 0.0 & 29.1 & 0.0 & & & & \\
\hline deviation & $\mathrm{f}$ & 165 & 91 & 0 & 0 & 40 & -1.7 & 1.5 & 4.15 & 1.32 \\
\hline prescription during healthcare & $\%$ & 55.7 & 30.7 & 0.0 & 0.0 & 13.5 & & & & \\
\hline deviation & $\mathrm{f}$ & 176 & 109 & 11 & 0 & 0 & -0.8 & -0.3 & 4.56 & 0.57 \\
\hline dispensation during healthcare & $\%$ & 59.5 & 36.8 & 3.7 & 0.0 & 0.0 & & & & \\
\hline Aggregated mean & & & & & & & & & 3.94 & 1.15 \\
\hline
\end{tabular}

Key: SA-Strongly agree, A-Agree, Un-Undecided, D-Disagree, SD-Strongly Disagree, Ske- Skewness, Kur-Kurtosis, S.DStandard deviation

Source: Survey data (2019)

The results in Table 4.13 indicate that more than half (162 forming 54.8\%) of the respondents (28.4\% strongly agreed, and $26.4 \%$ agreed) that 'Lexical deviation affects effective communication in assessment of medical conditions during the provision of quality healthcare'. The mean of this item was 3.31 and SD was 1.53 showing that the majority of respondents were in agreement with the statement. $18.9 \%$ (56) of the respondents were neutral on this matter while $26.4 \%$ (78) of the respondents felt that lexical deviation did not affect effective communication in assessment of medical conditions during the provision of quality healthcare. In relation to the effect of lexical deviation on effective communication in diagnosis of medical conditions during the provision of quality healthcare, majority (210 forming $70.9 \%$ ) of the respondents were in agreement with the statement. This constituted of 99 (33.4\%) strongly agreeing and 111 (37.5\%) agreeing. This affirmed that lexical deviation greatly affected effective communication $($ mean $=3.75$, S.D $=1.20) .29 .1 \%(86)$ of the respondents however disagreed, and thus indicated that lexical deviation did not affect effective communication in diagnosis of medical conditions. 
In regard to the effect of lexical deviation on effective communication in prescription of medical drugs during the provision of quality healthcare, the respondents indicated that they were generally in agreement with the statement $($ mean $=4.15, \mathrm{SD}=1.32)$. Specifically, $55.7 \%$ and $37.5 \%$ strongly agreed and agreed with the statement repectively. Only $13.5 \%$ of them disagreed with the statement.

Lastly, the statement that 'Lexical deviation affect effective communication in dispensation of medical drugs during the provision of quality health' was supported by $96.3 \%$ (mean $=4.56, \mathrm{SD}=0.57$ ) of the respondents. Strongly disagreeing attracted $59.5 \%$ while agreeing attracted $36.8 \%$ of the respondents. Only $3.7 \%$ remained neutral on the statement.

From table 4.13 , there was a general concurrence that grammatical distortion did not affect effective communication in assessment of medical condition during the provision of quality healthcare (aggregate mean $=3.94$ and S.D $=1.15$ ). The values of skewness and kurtosis indicated that phonology depicted a normal distribution as the values were within the interval of -2.0 and +2.0 recommended by Tabachnick and Fidell (2007).

Qualitative data from the patients indicated that lexical deviation affected effective communication during the provision of quality healthcare. In several occations, it was reported by the patients that:

Some words in the translated documents in most cases presented a disconnect..... This was very common in cases where they were tranlated in Kiswahili. (Patients 16, 24,29...).

Linear regression analysis was further sought. The regression model explored was:

$$
Y=\beta_{0}+\beta_{1} X+\varepsilon
$$

The variable $Y$ represented effective communication during the provision of quality healthcare and the variable $X$ represented lexical deviation in communication. The residual $\varepsilon$ represented departure of the observed values of effective communication from what the model could estimate.

Tests were initially done on model 4.4 to ascertain the relationship between adjacent residuals. The results indicated no correlation as presented in table 4.14. The Durbin-Watson statistic value was 1.785 with the recommended interval of 1 to 3 according to Field (2009). The results in Table 4.14indicated statistically significant positive correlation coefficient between lexical deviation and effective communication $(\mathrm{R}=.321 ; \mathrm{P}<.05)$ qualifying linearity of the relationship.

The initial assumptions were satisfied, and the effect of phonology in effective communication during the provision of quality healthcare was thus tested. The hypothesis that there is no statistically significant effect of phonology on effective communication for the provision of quality healthcare in Kericho Countyhealth facilitieswas therefore tested at 5\% significance level. The results are presented in the table below: 
h) Table 4.14: Linear regression analysis for the influence of facilities on performance

\begin{tabular}{lllllll}
\hline Model & $\begin{array}{l}\text { Unstandardized } \\
\text { Coefficients }\end{array}$ & $\begin{array}{l}\text { Standardized } \\
\text { Coefficients }\end{array}$ & t & Sig. \\
\cline { 3 - 6 } & $\mathrm{B}$ & Std. Error & Beta & & \\
\hline \multirow{2}{*}{$\begin{array}{l}\text { (Constant) } \\
\text { Lexical deviation }\end{array}$} & 5.365 & .813 & & 6.496 & .000 \\
& .465 & .104 & -.321 & 4.462 & .000
\end{tabular}

Goodness of fit:

$$
\begin{aligned}
R & =.321 \\
R^{2} & =.103
\end{aligned}
$$

Adjusted $R^{2}=.101$

$F(1,295)=38.560$

$$
P<.05
$$

Durbin-Watson:1.785

a. Dependent Variable: Academic performance

b. Independent Variable: Facilities

Source: Survey data (2019)

The table above showed that there was a statistically significant weak negative correlation $(\mathrm{R}=.321 ; \mathrm{P}<.05)$ between lexical deviation and effective communication during the provision of quality healthcare. The portion of effective communication which was attributed to lexical deviation was depicted by the value of $\mathrm{R}$-square which was .103. This value indicated that lexical deviation could approximately account for only $10.3 \%$ of effective communication during the provision of quality healthcare.

The value of the adjusted $\mathrm{R}$ square showed that if the entire population was used instead of the study sample, then the resultant model would account for approximately $.002(.2 \%)$ less variations in the findings. The value $F_{(1,295)}=38.560 ; \mathrm{P}<.05$ affirmed that the regression model was statistically significant hence the null hypothesis was rejected.

Considering the standardized beta coefficients, for one positive standard deviation in lexical deviation, effective communication during the provision of quality healthcare would be reduced by approximately .321 effectiveness.

\section{E. Discussion by objective}

The discussion of the research findings based on the research objectives was examined in this section as follows:

\subsubsection{Effect of phonology on effective communication for the provision of quality healthcare}

The first objective of the study was to examine the effect of phonology on effective communication for the provision of quality healthcare in the county health facilities. The study revealed that phonology affected effective communication in medical assessment as well as diagnosis of medical conditions in the facilities. This could be as a result of the fact that the county is 
cosmopolitan and the residents are drawn from different ethnic groups, and by extension races. Qualitative data also indicated that some of the patients could not easily understand the language of some of the medical staff because of their accents. These findings concurred with the earlier study by Blaser (2009) who indicated that phonetics may affect effective communication especially when the parties involved have different accents as a result of ethnic influence in their languages. Phonology thus plays a crucial role in enhancing effective communication as in: following the medical instructions (Gillon, 2004; Torgesen\&Mathes, 2002)

The study further indicated that majority of the respodents were not keen on the role of phonology on effective communication in prescription and dispensation of medical drugs. This was due to the fact that both prescription and dispensation was entirely done by the medical personnel after diagnosis and there was a tiny role played by the patient at this juncture. Qualitative data also indicated that some of the medical staff interviewed concurred. This finding did not agree with the earlier studies by Gillon (2004) who opined that phonology affect effective communication in the entire medication process.

The study consequently revealed statistically significant positive correlation coefficient between phonology and effective communication $(\mathrm{R}=.627$; $\mathrm{P}<.05)$ which was in line with the findings of Dodd et al. (2008) who also found a statistically significant positive effect of phonology competency on effective communication.

\subsubsection{Effect of mother tongue interference on effective communication for the provision of quality healthcare}

The second objective wanted to find out the effect of mother-tongue interference on effective communication for the provision of quality healthcare in Kericho County health facilities, Kenya. It found that mother tongue interference greatly affected (mean = 4.31 and S.D 0.64) effective communication in assessment of medical conditions during the provision of quality health care. This could be attributed to the fact that Kiswahili and English are the national and official languages in Kenya respectively and are used mostly in thesefacilities. Those who visit these facilities mostly prefer using their first languages. Further, it is effectively used in expressing emotions associated with health conditions hence the mostly used language in healthcare among patients (Bowen, 2001). These results also affirmed the initial findings by Collins et al. (2002) who asserted that native language interference can easily be noticed in communication and this inhibits effective communication.

It was also shown that there were variations on mother tongue interference on effective communication in diagnosis. Physicians could tell the conditions by observation or by examininationfrom the medical laboratories without communicating to the patient in question.

In using effective communication in prescription of medical drugs, mother tongue interference was also found to be a problem (92.6\%). Further, it did not affect dispensation of medical drugs during the provision of quality health care $(2.53$ and S.D $=1.43)$. The results conformed with the qualitative data from some of the patients interviewed who reported that it took time to speak to medical officers especially those who were not from their ethnicity as a result of mother tongue interference. Some patients also asserted that it was difficultto express some of the medical issues in English or Kiswahili. These results agreed with the earlier reports by Ali and Watson (2018) who indicated that language barrier was common in facilities which were visited by people 
from different ethnicities. They also posited that in cases where interpreters were involved, effective communication was slowed thus resulting in inappropriate healthcare to the patients in question.

\subsubsection{Effect of grammatical distortion on effective communication for the provision of quality healthcare}

The third objective was to determine the effect of grammatical distortion on effective communication for the provision of quality healthcare. The research findings revealed that grammatical distortion did not affect effective communication in assessment,diagnosis and prescription of medical conditionsin the provision of quality health care. This implied that regardless of the nature of grammatical structure used, the healthcare staff felt that what was necessary in medication was communication. It concured with the qualitative data from the patients' interview in which the patients interviewed indicated that correct grammar did not matter as long as the doctor could understand. Similarly, Derose and Baker (2002) also found that those who had a good language command made more hospital visits than those who could not communicate well.

\subsubsection{Effect of lexical deviation on effective communication for the provision of quality healthcare}

The fourth and last objective investigated the effect of lexical deviation on effective communication for the provision of quality healthcare. It was noted that lexical deviation affected effective communication in assessment of medical conditions (54.8\%). Those who translated one language to another in cases where the medical staff and patients could not communicate effectively were believed wrongly replaced certain words which could affect the process of medical assessment. These findings corroborates earlier findings byParadiset al. (2011) who asserted that while replacing words from one language to another, mistakes are sometimes made because the person involved may lack the linguistic competence necessary for fluent code-switching.

It was also noted that lexical deviation affected effective communication in the diagnosis of medical conditions (70.9\%), prescription $($ mean $=4.15, \mathrm{SD}=1.32)$, and dispensation of medical drugs $(4.56, \mathrm{SD}=0.57)$. This implied that the patients and the medical staff could not effectively communicate during diagnosis, prescription and dispensation as a result of language barrier created by lexical deviation. Theseconfirm earlier findings bySobralske (2011) who indicated that constant replacement of items during communication some of which may not be appropriate or relevant, contribute to lexical barrier in communication. The results were similar to the study by Anne-Marie et al. (2013) on Language adaptation in health care and health services: issues and strategies, who indicated that the use of translated documents and interpreters allow for communication but the understanding between the parties involved is not guaranteed 


\section{CHAPTER Five}

\section{SUMMARY OF FINDINGS, CONCLUSION AND RECOMMENDATIONS}

\section{F. 5.0 Introduction}

This Chapter presents the discussion of the research findings, summary of the key findings, conclusions, recommendations and suggestions for further research.

\section{G. 5.1 Summary of Key Findings}

First, the study examined the effect of phonology on effective communication for the provision of quality healthcare in Kericho County health facilities. The hypothesis of the study was that there was no statistically significant effect of phonology on effective communication for the provision of quality healthcare in the facilities. The results showed that phonology had a statistically significant positive correlation $(\mathrm{R}=.627 ; \mathrm{P}<.05)$ with effective communication during the provision of quality health care. Phonology accounted for approximately $39.3 \%$ of variations on effective communication during the provision of quality health care. The linear regression model relating phonology to effective communication during the provision of quality health care was statistically significant $\left(F_{(1,295)}=123.221 ; \mathrm{P}<.05\right)$. The null hypothesis was rejected. Phonology had a statistically significant effect on effective communication during the provision of quality health care in the facilities in the County.

Secondly the study sought to find out the effect of mother-tongue interference on effective communication for the provision of quality healthcare in the County health facilities. The hypothesis was that there is no statistically significant effect of mothertongue interference on effective communication for the provision of quality healthcare in the County health facilities. The findings indicated that mother tongue interference had a statistically significant negative correlation $(\mathrm{R}=.524 ; \mathrm{P}<.05)$ with effective communication during the provision of quality health care. Mother tongue interference accounted for approximately $27.5 \%$ of variations in effective communication during the provision of quality health care. The linear regression model relating mother tongue interference to effective communication during the provision of quality health care was statistically significant $(F$ $(1,295)=101.360 ; \mathrm{P}<.05)$. The null hypothesis was rejected. Mother tongue interference had a statistically significant effect on effective communication during the provision of quality health care in facilities in the County.

Third, the study was set to determine the effect of grammatical distortion on effective communication for the provision of quality healthcare in Kericho County health facilities, Kenya. The hypothesis was that there is no statistically significant effect of grammatical distortion on effective communication for the provision of quality healthcare in Kericho County health facilities, Kenya. The results showed that grammatical distortion had a statistically significant weak negative correlation $(\mathrm{R}=.215 ; \mathrm{P}<.05)$ with effective communication during the provision of quality health care. Grammatical distortion accounted for approximately only $4.6 \%$ of variations on effective communication during the provision of quality health care. The linear regression model relating phonology to effective communication during the provision of quality health care was statistically significant $\left(F_{(1,295)}=\right.$ 23.111; $\mathrm{P}<.05)$. The null hypothesis was rejected. Grammatical distortion had a statistically significant effect on effective communication during the provision of quality health care in facilities in Kericho County. 
Lastly, the study was set to investigate the effect of lexical deviation on effective communication for the provision of quality healthcare in the County health facilities. The hypothesis of the study was that there is no statistically significant effect of lexical deviation on effective communication for the provision of quality healthcare in Kericho County health facilities, Kenya. The findings indicated that lexical deviation had a statistically significant weak negative correlation $(\mathrm{R}=.321 ; \mathrm{P}<.05)$ with effective communication during the provision of quality health care. Lexical deviation accounted for approximately only $10.3 \%$ of variations on effective communication during the provision of quality health care. The linear regression model relating lexical deviation to effective communication during the provision of quality health care was statistically significant $\left(F_{(1,295)}=38.560\right.$; $\mathrm{P}<.05)$. The null hypothesis was rejected. Lexical deviation had a statistically significant effect on effective communication during the provision of quality health care in health facilities in Kericho County.

\section{H. 5.2 Conclusions}

Phonology had a statistically significant positive correlation on effective communication during the provision of quality health care. It accounted for variations in effective communication during the provision of quality healthcare in the health facilities. It therefore affected effective communication during the provision of quality healthcare in facilities in Kericho County.

Mother tongue interference had a statistically significant negative correlation with effective communication during the provision of quality health care. It accounted for variations in effective communication during the provision of quality health carein these facilities. It thusaffected effective communication during the provision of quality health care in health facilities in Kericho County.

Grammatical distortion had a statistically significant weak negative correlation with effective communication during the provision of quality health care. It also attributed to the variations in effective communication during the provision of quality health care in the facilities. Therefore it affected effective communication during the provision of quality health care in health facilities in the County.

Lexical deviation had a statistically significant weak negative correlation with effective communication during the provision of quality health care. It further accounted for variations in effective communication during the provision of quality health care in the facilities. Thus, it affected effective communication during the provision of quality health care in health facilities in the county. Based on the research findings, the recommendations are as follows:

i) Language barriers affected effective communication during the provision of quality health carein health facilities in Kericho County. Healthcare managers and other stakeholders in the sector should therefore understand the language needs of the facilities as this epitomizes risks for the health facilities in providing quality services.

ii) Further, the respective health facilities should seek the services of language interpreters especially in facilities which are visited by people from different ethnic groups.

iii) Translated materials of the most popular language in the County should be used by the healthcare staff to ease the communication process. 


\section{5.4 Suggestions for Further Research}

The current study has indicated that language barriers (phonology, mother tongue interference, grammatical distortion, and lexical deviations) affect effective communication during the provision of quality health care. However, the specified language barriers only affected a fraction of effective communication. Future research is needed to investigate other factors other than language barriers (i.e. phonology, mother tongue interference, grammatical distortion, and lexical deviations) which contribute to language barrier in effective communication.

\section{REFERENCES}

Abutalebi, J. (2008) Neural Aspect of Second Language Representation and Language Control. Act Psychological. Academy of Pediatrics, 111, 1, 6-14

Anne-Marie, O., Normand, T., Bilkis, V. \&Isabelle, H. (2013). Language Adaptation in Health Care and Health Services: Issues and Strategies.Institut national de santé publique du Québec.

Benson, C. (2002)Transfer / Cross - Linguistic Influence.ELT Journal 56 (1), 68-70

Bowen, S. (2001). Language barriers in access to healthcare. Ottawa - Health Canada.

Brown H.D. (2000)Principles of Language Learning \& Teaching $\left(4^{\text {th }}\right.$ Ed).Longman;San Francisco State University.

Carless, D. (2008)Student Use of the Mother Tongue in the Task - Based Classroom. ELT Journal 62 (4), $331-338$.

Carrasquillo O., Ovary E.J., Brennan T.A. \&Burstin H.R. (1999) Impact of Language barriers on Patient satisfaction in an Emergency Department. Journal of General Internal Medicine; 14:82-87.

David, R.A. \& M Rhee (1998) The Impact of language as a barrier to Effective Healthcare in Undeserved Urban Hispanic Community. Mt. Sinai Journal of Medicine 65(5,6); 393-397.

Ellis R. (1997).The Study of Second Language Acquisition. Oxford University Press.

Flores G., D. Gee, \& B. Kasmer. (2000). The Teaching of Cultural Issues in U.S. and Canadian Medical Schools. Academic Medicine $75(5): 451-455$

Flores, G. (2005). The OImpact of medical interpreter services on the quality of Health Care: A Systematic Review. Medical Care Research and Review. 62: 255-299

Flores G. (2006) Language Barriers to Healthcare in the United States [Electronic version]. The New England Journal of Medicine, 335 (3), $229-231$

Gillon, G.T. (2004). Phonological awareness: From research to practice. NewYork, NY: The Guilford Press. 
Grabeand, K. (1991)Introduction to Applied Linguistics; Second Language Professional Library; Addison - Wesley Publishing Company.

Hornberger, J.C., Gibson, C.D. Wood, W.Dequeldre, C. Corso, I. Palla, B. \& Bloch. D.A. (1996). Eliminating Language Barriers for Non-English-Speaking Patients. Medical Care34 (8): 845-856.

Kenya National Bureau of Statistics (KNBS). (2010).Statistical Abstract.Nairobi:KNBS.

Krashen, S.D. (1981) Second Language Acquisition and Second Language Learning. Oxford: Pergamon.

Krashen, S.D. (1982)Principles and Practice in Second Language Acquisition.Oxford: Pergamon.

Kothari, C. (2004), Research Methodology: Methods and Techniques, 2nd Revised Ed. New Age International Publishers.

Ladefoged P. (2001) A Course in Phonetics $\left(4^{\text {th }}\right.$ Ed)Heinle andHeinle. Los Angeles: University of California.

Lee, S.M. \& Pope,C.R.(2001). Patients Who Don't Speak English: Improving Language Minorities' Health Care with Professional Interpreters. Washington D.C.: Office of Minority Health, Department of Health and Human Services.

Mahmoud, A. (2006). Translation and Foreign Language Reading Comprehension: A Neglected Didactic Procedure. English Teaching Forum, 44 (4), 28-33.

Morales L.S., Cunningham W.E., Brown J.A., Liu H., \&Hays R.D (1999) Are Latinos less satisfied with Communication by Healthcare Providers?Journal of General Internal Medicine; 14, 409-417

Mugenda\&Mugenda (2004) “Research Design versus Research Instruments," McGraw Hill Publishing Company, New York, U.S.A

O’Connor, J.D (1980) Better English Pronunciation (2 ${ }^{\text {nd }}$ Ed) Cambridge: Cambridge University Press.

Torgesen, J. K., \&Mathes, P. G. (2002).Assessment and Instruction in Phonological Awareness. Second Edition. Florida Department of Education. Division of Public Schools and Community Education.

Woloshin, S., Bickell, N.A., Schwartz, L.M.,Gany, F.\&Welch,H.G. (1995). Language Barriers in Medicine in the United States. Journal of the American Medical Association 273 (9): 724-728.

Yule, G. (1996)The Study of Language ( $2^{\text {nd }}$ Ed) Cambridge: Cambridge University Press. 